\title{
Characterization of Enteric Isolates in Blood and Stool Specimens among Outpatients Presenting with Fever Symptoms in Crescent Medical Aid Facility, Nairobi County, Kenya
}

\author{
Musyoki $\mathrm{PM}^{1 *}$, Kangethe $\mathrm{SK}^{1}$ and Ozwara $\mathrm{H}^{2}$ \\ ${ }^{1}$ Department of Medical Laboratory Sciences, Mount Kenya University, Thika, Kenya \\ ${ }^{2}$ Director Institute of Primate Research National Museum of Kenya, Karen, Nairobi
}

${ }^{*}$ Corresponding author: Peter Mumo Musyoki, Department of Medical Laboratory Sciences, Mount Kenya University, P.O Box 342-01000, Thika, Kenya, Tel: +254-725247503; E-mail: pmmusyokipeter86@gmail.com

Received date: Nov 19, 2018; Accepted date: Dec 19, 2018; Published date: Dec 30, 2018

Copyright: (2018 Musyoki PM, et al. This is an open-access article distributed under the terms of the Creative Commons Attribution License, which permits unrestricted use, distribution, and reproduction in any medium, provided the original author and source are credited.

\begin{abstract}
Bacterial pathogens, which are acquired through consumption of contaminated water and food are a major contributor of morbidity and mortality and thus a public health concern in developing countries and this is brought about by the bacterial resistance to antimicrobial drugs used. Salmonella enterica serotype typhi causes enteric fever which is a waterborne and foodborne disease. A cross-sectional study was conducted in two clinics setting among the residents of Mukuru slum, Nairobi County on outpatients who had fever-like symptoms upon consent. A total of one hundred and fifty patients were sampled and their blood and stool samples collected. Subsequently, laboratory analysis was carried out characterize bacterial isolates and its antibiotic susceptibility profiles. From the culture of the stool and blood samples, 27 positive cultures of bacterial pathogens were detected with both gram positive $(28.3 \%)$ and gram negative $(71.7 \%)$ bacteria's. The blood isolate included Staphylococcus aureus $(2.7 \%)$, Proteus mirabilis $(0.7 \%)$ and Escherichia coli $(0.7 \%)$. The isolates from the stool culture were Escherichia coli $(18 \%)$ and Shigella dysentriae (4.7\%). Using Salmonella antigen test, 73 (39.3\%) samples tested positive for typhoid but none of the isolates of Salmonella typhi was seen in both blood and stool cultures. All the isolates indicated moderate to high resistance to ampicillin-cloxacillin $(23.3 \%)$, tetracycline $(6.7 \%)$ and cefuroxime $(8 \%)$, while the isolates were highly susceptibility to gentamicin $(23.3 \%)$, chloramphenicol $(13.3 \%)$ and ciprofloxacin $(22 \%)$. In conclusion, despite the fact Mukuru slums is not a malaria endemic region, the main cause of invasive bacteremia in patients presenting with fever-like symptoms is not $S$. typhi and therefore, there is need for improved diagnostic methods in patients presenting fever-like symptoms and should also be screened for other bacterial pathogens in addition to Salmonella in order to enhance proper treatment and overall control of multi-drug resistance because of misdiagnosis and improper prescription of antibiotics.
\end{abstract}

Keywords: Enteric isolates; Blood culture; Stool culture; Multi-drug resistant

\section{Introduction}

Enteric fever is a systemic enteric disease and is a leading cause of common febrile illness brought about by Salmonella enterica serovars typhi and Para typhi, which are gram-negative bacteria [1]. Enteric fever is a global public health problem has more than 27 million cases worldwide each year resulting in an estimated 217,000 deaths [2]. The clinical presentation of Enteric fever symptoms overlaps with those present during infections with other bacterial, viral and parasitic pathogen and thus nonspecific [3].

Salmonella typhi is mainly transmitted via the fecal-oral route and is associated with poor hygiene and sanitation conditions [4]. Majority of diarrheal bacterial pathogens are common to those patients presenting with fever-like symptoms and as indicated are poverty and hygiene outcomes. Studies carried out to establish the prevalence or incidences of $S$. typhi showed other bacterial pathogens in febrile patient samples presenting with fever-like symptoms that are commonly isolated alongside $S$. typhi in patients suspected of typhoid fever which included Staphylococcus species, Escherichia coli, Shigella species,
Klebsiella pneumonia, Enterobacter, Citrobacter and Streptococcus species [4].

Studies carried out on blood and stool samples of suspected Enteric fever patients in Kenya and Nigeria reported the presence of Staphylococcus aureus, Klebsiella pneumonia, Streptococcus species and non-typhoidal Salmonella species isolates [5]. In India, cases of coinfection with more than one bacterium have been reported whereby $S$. typhi was isolated in a preschool child with pneumonia [6]. Due to diversity and similarity in symptoms presenting in common febrile illness, to diagnose Enteric fever on the clinical ground alone present difficulties and possibilities of misdiagnosing [7]. However, to address this gap in the study area, this approach was meant to provide data and results correlating laboratory findings with the clinical presentation of the study participants. Therefore to manage Enteric fever cases there is wide use of serological methods and clinical presentation of the patient which is inefficient and insufficient since in most instances they are non-specific and thus resulting in rising cases of mistreatment, misprescription and misutilization of drugs because of misdiagnosis which has brought serious implications both at individual and society level [4]. Evidence-based diagnosis will require bacteriological isolation of the aetiological agent responsible for the infection. The capacity to isolate and identify the etiological agent is often not possible in the study facility where this study was done. This has lead to 
Citation: Musyoki PM, Kangethe SK, Ozwara H (2018) Characterization of Enteric Isolates in Blood and Stool Specimens among Outpatients Presenting with Fever Symptoms in Crescent Medical Aid Facility, Nairobi County, Kenya. Clin Microbiol 7: 322. doi: $10.4172 / 2327-5073.1000322$

Page 2 of 7

a paucity of data, pattern, and distribution of bacterial pathogens in the study clinics. Lack of facilities and capacities in a majority of resource strain setup Kenya included leads to empirical treatment of enteric fever associated illnesses guided by clinical manifestation and presentation of the patient on management or population under study in Nairobi County, Mukuru slums this problem is not except and there is a paucity of data in regard to enteric fever.

Empirical treatment as practiced in the research facilities assessable to the population is likely to lead into serious antimicrobial resistance creating a need to have laboratory-based evidence findings to bridge the data paucity currently existing in this study area. Enteric fever cases are high in Mukuru slums and continue to cause significant morbidity among the people of Mukuru slums, Nairobi County. There was a need to confirm experimentally if enteric fever was indeed common or the high cases reported were due to misdiagnosis since the clinical manifestation of enteric fever is non-specific and could resemble those of other clinical bacterial pathogens and since diarrhea, vomiting, abdominal pain, headache, splenomegaly, anorexia, and hepatomegaly are the most common symptoms associated with Enteric fever [8,9]. The culture of blood, bone marrow aspirates, stools or urine are the guidelines for the diagnosis of Enteric fever [9].

The study focused on blood and stool samples of those outpatients who presented with fever-like symptoms at Crescent Medical Aid facility located at Mukuru slums, Nairobi County.

The insufficient or inappropriate treatment has lead to unnecessary exposure of the patient to antibiotics in the case of a viral cause of febrile illness at the individual level [4]. This has brought about the emergence of multidrug resistance to those individuals who commonly use antibiotics for Enteric fever. The lack of correct diagnosis has made it difficult to monitor the transmission chain of Enteric fever, its determination to the carrier patients and the local transmission routes which are considered essential in containing diseases in case of an outbreak at the community level [4].

\section{Materials and Methods}

Following approval by Mount Kenya University Ethics Review Committee (Ref. NO.MKU/ERC/0087), research authorization by Crescent Medical Aid Kenya Administrator and research clearance Permit by National Commission for Science Technology and Innovation (NACOSTI/P/16/70475/9658), 150 respondents were recruited for the study using systematic sampling procedure.

\section{Sample size}

The sample size was determined using the Daniel Formula (1999).

Salmonella isolation rate of $9.17 \%$ by blood culture and a level of significance of $5 \%$, the sample size was calculated using formula as below:

$$
\begin{aligned}
& \mathrm{n}=(\mathrm{z})^{2} \mathrm{p}(1-\mathrm{p}) / \mathrm{d}^{2}: \text { Where } \\
& \mathrm{n}=\text { Sample size } \\
& \mathrm{z}=\text { Standard normal deviate at } 95 \% \text { confidence level }=(1.96) \\
& \mathrm{p}=\text { Estimated prevalence of Salmonella typhi } \\
& \mathrm{d}=\text { Degree of precision at } 5 \% \\
& \mathrm{n}=1.96^{2} \times 0.0917(1-0.0917) / 0.05^{2}=150 \text { patients samples }
\end{aligned}
$$

\section{Inclusion and exclusion criteria}

Inclusion criteria: Patients who had fever $\geq 37.5^{\circ} \mathrm{C}$ and had fever for the last three days which was confirmed; patients having fever $\geq 37.5^{\circ} \mathrm{C}$ for three days and blood slide for malaria parasites was positive; Patients who presented the signs and symptoms of enteric fever that is splenomegaly, diarrhea, vomiting, abdominal pain, palpable masses, hepatomegaly, anorexia among others; patients who for at least 14 days prior to hospital visit had not taken any antibiotics were included in this study upon consent exclusion criteria: patients who had signs and symptoms and were on antibiotics for forty nights prior to the hospital visit, patients having fever $\geq 37.5^{\circ} \mathrm{C}$ for three days and their blood slide for malaria parasites was negative. Patients who had no signs and symptoms of Enteric fever were excluded from this study.

\section{Sample collection and laboratory analysis}

The patient's blood and stool samples were collected at the Crescent Medical Aid Laboratory. The sample collection materials were clearly barcoded and based on the age bracket of the patient, $4 \mathrm{ml}$ of blood specimens were drawn by use of syringe and needle through vein puncture. About $2 \mathrm{ml}$ was transferred into commercially prepared sterile (EDTA) vacutainers for separation of serum for use in Salmonella antigen test which was performed according to manufacturer's instructions (Biogatelabs Ltd., Canada) and about $2 \mathrm{ml}$ into Hi-Combi dual performance medium. In addition, from each patient stool sample was ordered to assess their carrier status for Enteric fever. The specimens collected from the hospital were transported in a cool box to Institute of Primate Research for laboratory analysis.

\section{Blood cultures}

The commercially prepared blood culture media which was stored in the temperature range of between $6^{\circ} \mathrm{C}$ and $8^{\circ} \mathrm{C}$ according to manufacturer's instructions (Oxoid Ltd., UK). The blood culture was incubated at $37^{\circ} \mathrm{C}$ after inoculation and turbidity and hemolysis observed daily for two weeks. The growth was indicated by the appearance of turbidity in the bottles and once this occurred, $1 \mathrm{ml}$ of the suspension was drawn and put in a sterile bijou bottle for subculture in different agars.

\section{Sub-cultures onto agars}

Sub-cultured was done on blood agar on the Positive cultures, MacConkey agar, and Salmonella-Shigella (S.S) agar and then incubated overnight at $37^{\circ} \mathrm{C}$. To detect any Streptococcus pneumoniae an optochin disk was placed onto the blood agar plate. The plates were then examined for growth after 24 hours and if no growth was seen, the plates were further incubated for an additional 24 hours. A standard identification procedure was done to those colonies that had grown.

\section{Stool cultures}

$10 \mathrm{ml}$ selenite $\mathrm{F}$ broth, which was prepared as per the manufacturer's instructions (Himedia, 2012, India) was used to inoculate approximately 1 gram of stool and incubated at $37^{\circ} \mathrm{C}$ for 18 to 48 hours. After turbidity was observed, subculture was performed on MacConkey and Salmonella-Shigella agar by use of sterile wire loop whereby a stab was made on the surface of the broth without disturbing the sediment and the inoculation done on the agar plates 
Citation: Musyoki PM, Kangethe SK, Ozwara H (2018) Characterization of Enteric Isolates in Blood and Stool Specimens among Outpatients Presenting with Fever Symptoms in Crescent Medical Aid Facility, Nairobi County, Kenya. Clin Microbiol 7: 322. doi: $10.4172 / 2327-5073.1000322$

Page 3 of 7

and then incubated at $37^{\circ} \mathrm{C}$ for 18 to 48 hours. The phenotypic characteristics of the colonies observed on the growth were described and recorded in the patient's record book before standard identification procedures were performed which included colony morphology and gram stain. Briefly, the key characteristics investigated to identify the isolates included lactose fermentation on MacConkey's and Salmonella-Shigella agar (Oxoid Ltd., UK) and hemolysis on blood agar (Oxoid Ltd., UK). According to Cheesbrough by use of a single colony, gram stain was done so as to differentiate the gram-positive bacteria from the gram-negative ones and the results noted.

\section{Antimicrobial susceptibility testing}

All the isolates were subjected to Antimicrobial susceptibility as described by [10]. Commercially prepared single antibiotic discs used included ampicillin-cloxacillin $(10 \mu \mathrm{g})$, amoxicillin-clavulanic acid (30 $\mu \mathrm{g})$, ceftazidime $(30 \mu \mathrm{g})$, chloramphenicol $(30 \mu \mathrm{g})$, ciprofloxacin $(5 \mu \mathrm{g})$, gentamicin $(10 \mu \mathrm{g})$, cefuroxime $(30 \mu \mathrm{g})$, tetracycline $(30 \mu \mathrm{g})$ and cotrimoxazole $(25 \mu \mathrm{g})$. To test sensitivity, Muller Hinton agar (Oxoid Ltd., UK) was used and this was done by inoculating the test organism by use of sterile wire loop, which picked and emulsified the test organism in a sterile bijou bottle by use of normal saline before streaking on Muller Hinton agar plate. By use of a swab, the entire agar surface of the plate was streaked and the inoculums allowed to dry for 5-10 minutes with the lid in place. Then by use of sterile forceps, the single antimicrobial discs were then incubated at $37^{\circ} \mathrm{C}$ within 18 to 24 hours. Examination for growth was done after overnight incubation and those plates with no growth were further incubated until the 24hour limit.

The radius of each inhibition zone was measured in millimeters and the value doubled to get the diameter by use of a ruler on the plate underside. The susceptibility of the isolate and the drug diffusion rate through the Muller Hinton agar medium was related to the diameter zone obtained after measurement and its inhibition zones read, results analyzed and presented using standardized thresholds for defining susceptibility as indicated. The results were presented as either sensitive, resistant or intermediate while Escherichia coli was used as a control strain.

To ensure that quality results were produced, quality control check was done on all the media used with controls obtained from Kenya Medical Research Institute (KEMRI)-Centre for Microbiology Research, Kenya (CMR). Since this aspect was considered, no contaminants were present in the media that could lead to the inhibition of bacteria pathogens growth which could be present in both blood and stool.

\section{Data management and statistical analysis}

Questionnaire responses and both blood culture results and stool culture results were entered into excel software and transferred to statistical package for social sciences (SPSS) version 20.0 for analysis. The distribution of entero-pathogens amongst the population was analyzed using the Chi-square test. To analyze the relationship between the Salmonella Antigen test outcome and the age and gender of the participants the chi-square test was used. A p-value of $\leq 0.05$ was used as it's significant.

\section{Result}

The observed clinical signs were positively correlated to Salmonella Antigen test $(\mathrm{r}=0.134, \mathrm{p}=0.103)$, blood culture results $(\mathrm{r}=0.012$, $\mathrm{p}=0.889)$ and stool results $(\mathrm{r}=0.137, \mathrm{p}=0.095)$. However, this relationship was weak and not statistically significant (Table 1). Of the 150 patients, the majority of the patients (96\%) did not have isolates in their blood culture results. However, there were some isolates of Staphylococcus aureus obtained from blood culture results of $2.7 \%$ of the patients while some isolates of Proteus-mirabilis (0.7\%) and some growth of E. coli $(0.7 \%)$ were obtained in blood culture results of the patients.

\begin{tabular}{|l|l|c|c|c|c|}
\hline \multicolumn{2}{|c|}{} & $\begin{array}{c}\text { Observe } \\
\text { d clinical } \\
\text { sign }\end{array}$ & $\begin{array}{c}\text { Salmonell } \\
\text { a Antigen } \\
\text { test }\end{array}$ & $\begin{array}{c}\text { Blood } \\
\text { cultur } \\
\text { e } \\
\text { results }\end{array}$ & $\begin{array}{c}\text { Stool } \\
\text { Culture } \\
\text { Results }\end{array}$ \\
\hline $\begin{array}{l}\text { Observed } \\
\text { clinical sign }\end{array}$ & Pearson Correlation & 1 & 0.134 & 0.012 & 0.137 \\
\cline { 2 - 6 } & Sig. (2-tailed) & & 0.103 & 0.889 & 0.095 \\
\hline $\begin{array}{l}\text { Salmonella } \\
\text { antigen test }\end{array}$ & Pearson Correlation & 0.134 & 1 & $0.225^{* *}$ & $0.544^{* *}$ \\
\cline { 2 - 6 } & Sig. (2-tailed) & 0.103 & & 0.006 & 0 \\
\hline $\begin{array}{l}\text { Blood } \\
\text { culture } \\
\text { results }\end{array}$ & Pearson Correlation & 0.012 & $0.225^{* *}$ & 1 & 0.155 \\
\cline { 2 - 6 } & Sig. (2-tailed) & 0.889 & 0.006 & 0.059 \\
\hline $\begin{array}{l}\text { Stool } \\
\text { culture } \\
\text { results }\end{array}$ & Pearson Correlation & 0.137 & $0.544^{* *}$ & 0.155 & 1 \\
\cline { 2 - 6 } & Sig. (2-tailed) & 0.095 & 0 & 0.059 & \\
\hline \multirow{2}{*}{ **. Correlation is significant at the 0.01 level (2-tailed) } & & \\
\hline
\end{tabular}

Table 1: Correlation of clinical signs with laboratory findings.

A great number of patients (76.7\%) did not have pathogenic isolates in their stool culture results. But the results indicate that there were isolates of Escherichia coli in stool culture results of $18 \%$ of patients and Shigella dysentery isolates in $4.7 \%$ of the patients. In stool culture results of $0.7 \%$ of the patients, there were some isolates of Proteus mirabilis.

By use of several antibiotics, the isolates obtained from both stool and blood culture were subjected to sensitivity testing followed by comparison using the standard interpretive chart for antibiotic susceptibility pattern. In blood culture, Staphylococcus aureus was resistant to Ampicillin-cloxacillin and intermediate to Cefuroxime and Cotrimoxazole (Table 2). Staphylococcus aureus was also intermediate to Ciprofloxacin and Tetracycline (Table 2). Proteus mirabilis was sensitive to Ampicillin-cloxacillin and Cefuroxime (Table 2). In addition, E. coli was intermediate to Ampicillin-cloxacillin, Ceftazidime, and Cotrimoxazole (Table 2).

In blood culture, Staphylococcus aureus was observed to be susceptible to Gentamicin and intermediate to Ciprofloxacin, Cotrimoxazole, and Chloramphenicol (Table 3). It was also observed to be resistant to Cefuroxime. Staphylococcus was not susceptible to Ceftazidine (Table 3). Proteus-mirabilis was found to be intermediate to Gentamicin, Ciprofloxacin, and Cotrimoxazole (Table 3). However, Proteus-mirabilis was not susceptible to Chloramphenicol, Cefuroxime, and Ceftazidine (Table 3). E. coli species were observed to be intermediate to Gentamicin, Ciprofloxacin, and Ceftazidine (Table 
Citation: Musyoki PM, Kangethe SK, Ozwara H (2018) Characterization of Enteric Isolates in Blood and Stool Specimens among Outpatients Presenting with Fever Symptoms in Crescent Medical Aid Facility, Nairobi County, Kenya. Clin Microbiol 7: 322. doi: $10.4172 / 2327-5073.1000322$

Page 4 of 7

3). However, E. coli was resistance to Cotrimoxazole, Chloramphenicol, and Cefuroxime (Table 3).

\begin{tabular}{|c|c|c|c|c|c|c|c|}
\hline & \multicolumn{6}{|c|}{ Dichotomy variables for resistance } & Total \\
\hline & AX & CXM & CAZ & CIP & TE & СОT & \multirow[b]{2}{*}{29} \\
\hline \multirow[t]{2}{*}{ No isolates } & 29 & 9 & 14 & 1 & 9 & 16 & \\
\hline & $82.90 \%$ & $\begin{array}{c}25.70 \\
\%\end{array}$ & $\begin{array}{c}40.00 \\
\%\end{array}$ & $\begin{array}{c}2.90 \\
\%\end{array}$ & $\begin{array}{c}25.70 \\
\%\end{array}$ & $\begin{array}{c}45.70 \\
\%\end{array}$ & $82.90 \%$ \\
\hline \multirow{2}{*}{$\begin{array}{l}\text { Isolates of } \\
\text { Staphylococc } \\
\text { us obtained }\end{array}$} & 4 & 2 & 1 & 1 & 1 & 2 & 4 \\
\hline & $11.40 \%$ & $5.70 \%$ & $2.90 \%$ & $\begin{array}{c}2.90 \\
\%\end{array}$ & $2.90 \%$ & $5.70 \%$ & $11.40 \%$ \\
\hline \multirow{2}{*}{$\begin{array}{l}\text { Isolates of } \\
\begin{array}{l}\text { Proteus- } \\
\text { mirabilis }\end{array}\end{array}$} & 1 & 1 & 0 & 0 & 0 & 0 & 1 \\
\hline & $2.90 \%$ & $2.90 \%$ & $0.00 \%$ & $\begin{array}{c}0.00 \\
\%\end{array}$ & $0.00 \%$ & $0.00 \%$ & $2.90 \%$ \\
\hline \multirow{2}{*}{$\begin{array}{l}\text { Isolates of } E \text {. } \\
\text { coli obtained }\end{array}$} & 1 & 0 & 1 & 0 & 0 & 1 & 1 \\
\hline & $2.90 \%$ & $0.00 \%$ & $2.90 \%$ & $\begin{array}{c}0.00 \\
\%\end{array}$ & $0.00 \%$ & $2.90 \%$ & $2.90 \%$ \\
\hline \multirow[t]{2}{*}{ Total } & 35 & 12 & 16 & 2 & 10 & 19 & 35 \\
\hline & $\begin{array}{c}100.00 \\
\%\end{array}$ & $\begin{array}{c}34.30 \\
\%\end{array}$ & $\begin{array}{c}45.70 \\
\%\end{array}$ & $\begin{array}{c}5.70 \\
\%\end{array}$ & $\begin{array}{c}28.60 \\
\%\end{array}$ & $\begin{array}{c}54.30 \\
\%\end{array}$ & $\begin{array}{c}100.00 \\
\%\end{array}$ \\
\hline
\end{tabular}

KEY: AX: Ampicillin-Cloxacillin; CXM: Cefuroxime; CAZ: Ceftazidine; CIP: Ciprofloxacin; COT: Cotrimoxazole; TE: Tetracycline

Table 2: Blood culture isolates showing antibiotic resistance.

\begin{tabular}{|c|c|c|c|c|c|c|c|}
\hline & \multicolumn{6}{|c|}{ Dichotomy variables for susceptibility } & \multirow[t]{2}{*}{ Total } \\
\hline & GEN & CIP & сот & CAZ & C & CXM & \\
\hline \multirow{2}{*}{$\begin{array}{l}\text { No } \\
\text { isolates }\end{array}$} & 29 & 28 & 5 & 8 & 17 & 0 & 29 \\
\hline & $82.90 \%$ & $\begin{array}{c}80.00 \\
\%\end{array}$ & $\begin{array}{c}14.30 \\
\%\end{array}$ & $22.90 \%$ & $48.60 \%$ & $\begin{array}{c}0.00 \\
\%\end{array}$ & $82.90 \%$ \\
\hline \multirow{2}{*}{$\begin{array}{l}\text { Isolates of } \\
\text { S. aureus }\end{array}$} & 4 & 3 & 2 & 0 & 3 & 1 & 4 \\
\hline & $11.40 \%$ & $8.60 \%$ & $5.70 \%$ & $0.00 \%$ & $8.60 \%$ & $\begin{array}{c}2.90 \\
\%\end{array}$ & $11.40 \%$ \\
\hline \multirow{2}{*}{$\begin{array}{l}\text { Isolates of } \\
P . \\
\text { mirabilis }\end{array}$} & 1 & 1 & 1 & 0 & 0 & 0 & 1 \\
\hline & $2.90 \%$ & $2.90 \%$ & $2.90 \%$ & $0.00 \%$ & $0.00 \%$ & $\begin{array}{c}0.00 \\
\%\end{array}$ & $2.90 \%$ \\
\hline \multirow{2}{*}{$\begin{array}{l}\text { Isolates of } \\
\text { E. coli }\end{array}$} & 1 & 1 & 0 & 1 & 0 & 0 & 1 \\
\hline & $2.90 \%$ & $2.90 \%$ & $0.00 \%$ & $2.90 \%$ & $0.00 \%$ & $\begin{array}{c}0.00 \\
\%\end{array}$ & $2.90 \%$ \\
\hline \multirow[t]{2}{*}{ Total } & 35 & 33 & 8 & 9 & 20 & 1 & 35 \\
\hline & $\begin{array}{c}100.00 \\
\%\end{array}$ & $\begin{array}{c}94.30 \\
\%\end{array}$ & $\begin{array}{c}22.90 \\
\%\end{array}$ & $25.70 \%$ & $57.10 \%$ & $\begin{array}{c}2.90 \\
\%\end{array}$ & $\begin{array}{c}100.00 \\
\%\end{array}$ \\
\hline
\end{tabular}

KEY: GEN: Gentamicin; CIP: Ciprofloxacin; COT: Cotrimoxazole; CAZ: Ceftazidine; C: Chloramphenicol; CXM: Cefuroxime

Table 3: Blood culture isolates showing antibiotic susceptibility.

In stool culture, Escherichia coli species was observed to be highly resistant to Ampicillin-cloxacillin and intermediate to Cotrimoxazole
(Table 4). The same species have also shown resistance to Ceftazidine and sensitivity to Tetracycline and Cefuroxime (Table 4). E. coli was sensitive to Ciprofloxacin (Table 4). Shigella dysenteriae was noted to be resistant to Ampicillin-cloxacillin and intermediate to Cotrimoxazole, Ceftazidime, Tetracycline, and Cefuroxime. However, Shigella dysenteriae did not show any resistance to Ciprofloxacin (Table 4).

\begin{tabular}{|l|l|l|l|l|l|l|l|}
\hline \multirow{2}{*}{} & \multicolumn{6}{|l|}{ Dichotomy variables for resistance } & \multicolumn{2}{l|}{ Total } \\
\cline { 2 - 8 } & $\mathbf{A X}$ & $\mathbf{C X M}$ & $\mathbf{C A Z}$ & $\mathrm{CIP}$ & $\mathrm{TE}$ & $\mathbf{C O T}$ & \\
\hline \multirow{2}{*}{$\begin{array}{l}\text { Isolates of } \\
\text { E. coli }\end{array}$} & 27 & 8 & 13 & 1 & 7 & 16 & 27 \\
\cline { 2 - 8 } & $79.40 \%$ & $\begin{array}{l}23.50 \\
\%\end{array}$ & $\begin{array}{l}38.20 \\
\%\end{array}$ & $\begin{array}{l}2.90 \\
\%\end{array}$ & $\begin{array}{l}20.60 \\
\%\end{array}$ & $\begin{array}{l}47.10 \\
\%\end{array}$ & $79.40 \%$ \\
\hline $\begin{array}{l}\text { Isolates of } \\
\text { Shigella } \\
\text { dysenteria } \\
\text { e }\end{array}$ & 7 & 3 & 3 & 0 & 2 & 3 & 7 \\
\hline \multirow{2}{*}{ Total } & $20.60 \%$ & $8.80 \%$ & $8.80 \%$ & $\begin{array}{l}0.00 \\
\%\end{array}$ & $5.90 \%$ & $8.80 \%$ & $20.60 \%$ \\
\cline { 2 - 7 } & $\begin{array}{l}100.00 \\
\%\end{array}$ & $\begin{array}{l}32.40 \\
\%\end{array}$ & $\begin{array}{l}47.10 \\
\%\end{array}$ & $\begin{array}{l}2.90 \\
\%\end{array}$ & $\begin{array}{l}26.50 \\
\%\end{array}$ & $\begin{array}{l}55.90 \\
\%\end{array}$ & $\begin{array}{l}100.00 \\
\%\end{array}$ \\
\hline
\end{tabular}

KEY: AX: Amplicillin-Cloxacillin; CXM: Cefuroxime; CAZ: Ceftazidine; CIP: Ciprofloxacin; COT: Cotrimoxazole; TE: Tetracyline

Table 4: Stool culture isolates antibiotic resistance.

In stool culture, Escherichia coli species was observed to be highly susceptible to Gentamicin and Ciprofloxacin but found to be intermediate to Chloramphenicol and resistance to Cotrimoxazole, Ceftazidine, and Cefuroxime (Table 5). Shigella dysenteriae was noted to be susceptible to Gentamicin and Ciprofloxacin (Table 5). The same species was intermediate to Chloramphenicol and Cotrimoxazole while it was resistance to Ceftazidime. In stool culture, Shigella dysenteriae was resistance to Cefuroxime (Table 5).

\begin{tabular}{|c|c|c|c|c|c|c|c|}
\hline & \multicolumn{6}{|c|}{ Dichotomy variables for susceptibility } & \multirow[t]{2}{*}{ Total } \\
\hline & GEN & CIP & сот & CAZ & c & CXM & \\
\hline \multirow{2}{*}{$\begin{array}{l}\text { Isolates of } \\
\text { Escherichi } \\
\text { a coli }\end{array}$} & 27 & 26 & 5 & 8 & 16 & 1 & 27 \\
\hline & $79.40 \%$ & $76.50 \%$ & $14.70 \%$ & $\begin{array}{c}23.50 \\
\%\end{array}$ & $\begin{array}{c}47.10 \\
\%\end{array}$ & $2.90 \%$ & $79.40 \%$ \\
\hline \multirow{2}{*}{$\begin{array}{l}\text { Isolates of } \\
\text { Shigella } \\
\text { dysenteria } \\
\text { e }\end{array}$} & 7 & 7 & 2 & 1 & 3 & 0 & 7 \\
\hline & $20.60 \%$ & $20.60 \%$ & $5.90 \%$ & $2.90 \%$ & $8.80 \%$ & $0.00 \%$ & $20.60 \%$ \\
\hline \multirow[t]{2}{*}{ Total } & 34 & 33 & 7 & 9 & 19 & 1 & 34 \\
\hline & $\begin{array}{c}100.00 \\
\%\end{array}$ & $97.10 \%$ & $20.60 \%$ & $\begin{array}{c}26.50 \\
\%\end{array}$ & $\begin{array}{c}55.90 \\
\%\end{array}$ & $2.90 \%$ & $\begin{array}{c}100.00 \\
\%\end{array}$ \\
\hline
\end{tabular}

KEY: GEN: Gentamicin; CIP: Ciprofloxacin; COT: Cotrimoxazole; CAZ: Ceftazidine; C: Chloramphenicol; CXM: Cefuroxime

Table 5: Stool culture isolates antibiotic susceptibility. 
Citation: Musyoki PM, Kangethe SK, Ozwara H (2018) Characterization of Enteric Isolates in Blood and Stool Specimens among Outpatients Presenting with Fever Symptoms in Crescent Medical Aid Facility, Nairobi County, Kenya. Clin Microbiol 7: 322. doi: $10.4172 / 2327-5073.1000322$

Page 5 of 7

\section{The distribution pattern of the Enteropathogens among the study participants}

The blood culture results had 4 Staphylococcus aureus isolates, 3 of which were obtained from patients residing in Nairobi while 1 was residing outside Nairobi. There were 1 Proteus-mirabilis isolate obtained from a patient who resides outside of Nairobi and 1 Escherichia coli isolate obtained from a patient residing in Nairobi. In stool culture results, there were 27 Escherichia coli isolates and 12 of these were from patients residing outside Nairobi, while 15 were from those patients residing in Nairobi. There were 7 Shigella dysenteriae of which 3 were obtained from patients residing outside Nairobi while 4 were obtained from patients residing in Nairobi. There were only 1 Proteus-mirabilis isolate obtained from a patient residing in Nairobi. There was no significant difference as illustrated in Table 6. Based on gender, occupation, residence, age or clinic of the patients from which these isolates were obtained.

\begin{tabular}{|l|c|c|c|c|c|c|}
\hline \multirow{2}{*}{ Variable } & \multicolumn{2}{|c|}{$X^{2}$} & \multicolumn{2}{c|}{ Df } & \multicolumn{2}{c|}{ P } \\
\cline { 2 - 7 } & Blood & Stool & Blood & Stool & Blood & Stool \\
\hline Gender & 3.441 & 1.286 & 3 & 3 & 0.328 & 0.733 \\
\hline Occupation & 10.675 & 8.306 & 9 & 9 & 0.299 & 0.504 \\
\hline Residence & 2.587 & 0.796 & 3 & 3 & 0.46 & 0.85 \\
\hline Age & 12.182 & 8.474 & 15 & 15 & 0.665 & 0.903 \\
\hline
\end{tabular}

$\mathrm{X}^{2}$ : Chi square; Df: Degree of freedom; P: P value

Table 6: Distribution of Enteropathogen based on the gender, occupation, residence and age of the study patients.

\section{Discussion}

This study revealed that observed clinical signs had a weak correlation with laboratory findings that included Salmonella Antigen test, blood culture results, and stool culture results. From the study participants who presented with signs and symptoms of Enteric fever infection, there were no blood cultures or stool cultures that confirmed positive results for $S$. typhi. The $S$. aureus, P. mirabilis, and $E$. coli were the specific bacterial pathogens isolated from the blood cultures done and these findings concur with studies done in Tanzania and Kenya where similar bacterial pathogens indicated the cause of bacteremia $[11,12]$. The findings further illustrate the importance of gramnegative bacteria in causing bacteremia as observed in South Korea, where increasing incidences of bloodstream infections as a result of antibiotic resistance gram-negative bacilli was observed [7].

The cultures done in this study yielded very few organisms and since was done using commercially prepared media which was incubated at the right temperature and routinely observed for growth, these low yield as observed from the study could be attributed by a number of reasons. Firstly, all the patients used in the study were outpatients who were relatively healthy thus it was believed that the bacteremia had not significantly affected them health wise. In most findings where high levels of bacteremia are documented, the study participants mostly consist of in-patients who are hospitalized with significant disease level [13]. A delayed diagnosis of bacteremia including Enteric fever could also result in low yield.

Performing blood cultures in the first week of infection will produce best results and this requires keen diagnosis by the clinician and early presentation by the patients to the hospital, but this was not the case in the study area since there were delayed hospital visits by the patients until the disease had progressed. Also, most of the patients are lowincome earners while the others are jobless from the neighboring slums, and because of this poverty they could not afford the cost of treatment in hospital and due to this most patients have several pretreatment options usually with available local concoctions such as Warbugia ugandensis and Plectranthus barbatus provided by the herbalist and analgesics which they usually use with the hope that the infection will clear away [14]. This was a move to cut costs incurred during hospital visits as well as purchasing of medicine prescribed. The use of antibiotics before visiting the hospital has shown to have a bactericidal effect on the bacteria thus preventing their growth in the culture medium [15]. The reliance on a single blood and stool cultures results as opposed to multiple cultures that are known to increase culture yields could be another reason for the low yield of cultures performed. Additionally, since all the participants were outpatients follow up of the patients was very difficult.

There is need to employ the use of automatic culture systems and the addition of resins in the culture specimens to absorb antibiotics present so as to increase the yield in blood culture outcomes for improved diagnostic methods although it is costly, [5]. The findings in this illustrated that most of the patients had a negative Salmonella Antigen test, had no isolates in their blood culture results and did not have pathogenic isolates in their stool culture results. Comparing the three tests, the Salmonella test gave the most patients with positive results followed by stool culture results while blood culture results gave the least number of patients with positive results.

Most of the bacterial isolates were resistant to Ampicillin-cloxacillin and Cotrimoxazole while the least were resistant to Ciprofloxacin. The results also indicated that most isolates were susceptible to Gentamicin and Ciprofloxacin while very few isolates were susceptible to Cefuroxime. There was remarkable resistance to some of the empirical formulas used to treat bacterial infections. In both stool and blood, most of the isolates were resistant to Ampicillin-cloxacillin, Tetracycline, and Cefuroxime. The increasing high usage of orally administered Cefuroxime could have attributed the high levels of resistance of the blood isolates.

When patients fail to adhere to the specified dosages or when they fail to clear the drugs prescribed resistance for orally administered drugs does occur. The isolates indicated intermediate to tetracycline (33.3\%) which is commonly used in adults and these results were in agreement with a study conducted in Tanzania to establish the causative agents of bloodstream infections and their antimicrobial susceptibility [12]. For the individual species, the results show that in blood culture Staphylococcus aureus were resistance to Ampicillincloxacillin and intermediate to Cefuroxime and Cotrimoxazole while susceptibility was observed to Ciprofloxacin and Tetracycline. This did not concur with the findings of a study done in Nigeria whereby $S$. aureus isolates indicated high susceptibility to Ampicillin-cloxacillin and Tetracycline [16].

The findings from the present study correlate to the bacteremia prevalence documented in Addis Ababa, Ethiopia (11.6\%) but were lower compared to that of research conducted in Northern Tanzania (16.4\%), North Western Tanzania (14.6\%) and Khartum North Hospital, Sudan (14.0\%) [17]. This variation could have resulted as a result of a difference in the social habit of the community, the personal hygiene standard, education, and the environment. Nighty five percent of the bacterial isolates indicated Multidrug resistance (MDR- 
Citation: Musyoki PM, Kangethe SK, Ozwara H (2018) Characterization of Enteric Isolates in Blood and Stool Specimens among Outpatients Presenting with Fever Symptoms in Crescent Medical Aid Facility, Nairobi County, Kenya. Clin Microbiol 7: 322. doi: $10.4172 / 2327-5073.1000322$

Page 6 of 7

resistance in $>2$ drugs). In a specialized hospital in Ethiopia, Addis Ababa, a $74 \%$ of findings was documented and this informed that multidrug resistance was high on those areas where antibiotics were commonly used [16]. The lack of appropriate infection control strategies which leads to an increase in the prevalence of resistance organism in the community has been brought out by the antibiotic use and abuse, thus increasing antibiotic resistance. The differences in the susceptibility profiles of $S$. aureus in this study could be associated with the observed alterations of resistance and susceptibility of $S$. aureus at relatively high temperatures [17].

Proteus-mirabilis isolates were intermediate to Ampicillincloxacillin and Cefuroxime while $E$. coli revealed susceptibility to Ampicillin-cloxacillin, Ceftazidine, and Cotrimoxazole. This concurred with the study done in Delhi India on resistance patterns of bacterial isolates obtained from bloodstream infections, where the resistance of E. coli to cefuroxime and amoxicillin-clavulinic acid was observed [6]. In the same finding relative susceptibility to chloramphenicol, ciprofloxacin and gentamicin were increased [6], a case similar to this study findings. However, this data does not concur with results obtained in the UK and Ireland where the resistance of the E. coli isolates to ceftazidime, cefotaxime, ciprofloxacin, and gentamicin was reported and this could be due to the upsurge of Cefuroxime Extended-Spectrum B-Lactamases (ESBLs) [8].

The Staphylococcus was susceptible to Gentamicin and moderately susceptible to Ciprofloxacin, Cotrimoxazole, and Chloramphenicol, but not susceptible to Ceftazidime. Proteus-mirabilis was only intermediate to Gentamicin, Ciprofloxacin, and Cotrimoxazole. However, it was not susceptible to Chloramphenicol, Cefuroxime, and Ceftazidime. E. coli was intermediate to Gentamicin, Ciprofloxacin, and Ceftazidine while it shows no susceptibility to Cotrimoxazole, Chloramphenicol and Cefuroxime. The mutation changes that occur as a result of organisms colonization in different habitats brings slight different in susceptibility patterns of $E$. coli isolates in blood and stool. The common bacterial pathogen isolated in Kenya as reported in a study done to assess bacteremia on children admitted to a rural hospital in Kenya where seven isolates were obtained is Proteus mirabilis [6].

There was a similarity in the enteropathogens isolates to those isolated in the stool of patients in a study done in Vientiane [18], which were E. coli and Shigella dysenteriae bacteria pathogens. The antibiogram indicated that all the enteropathogens were susceptible to chloramphenicol, ciprofloxacin and gentamicin drugs used and this concurred with the research conducted in Nigeria and Kenya in which high susceptibility was also observed [16]. There is increasingly widespread multi-drug resistance to the empirical formulas used to clear away bacterial infection and thus this was a welcome relief.

Other antibiotics such as amoxyclavulin acid, ceftazidime, and cotrimoxazole with relative susceptibilities are useful in clearing bacterial infections in the study area. From the study findings, it is evident that the communities do practice self-medication with anti-malarial drugs which are in part useful as it serves to reduce the widespread multidrug resistance to antibiotics and this is highly unlikely that the resistance patterns observed could have been due to this selfmedication with antibiotics.

In stool culture, E. coli was resistant to Ampicillin-cloxacillin and intermediate to Cotrimoxazole. The resistant was also observed with Ceftazidine and shown a little resistance to Tetracycline and Cefuroxime while it has shown susceptibility to Ciprofloxacin. Shigella dysenteriae was resistant to Ampicillin-cloxacillin while intermediate was observed in Cotrimoxazole, Ceftazidime, Tetracycline, and Cefuroxime. It did not show any resistance to Ciprofloxacin. E. coli was found to be highly susceptible to Gentamicin and Ciprofloxacin and intermediate to Chloramphenicol. It also showed intermediate to Cotrimoxazole and Ceftazidine and resistant to Cefuroxime. Shigella dysenteriae was found to be susceptible to Gentamicin and Ciprofloxacin, intermediate to Chloramphenicol and Cotrimoxazole and also resistant to Ceftazidime. It was not found to be susceptible to Cefuroxime. From the gender, occupation, residence, age or clinic of the patients from which the isolates were obtained, there were no significant differences.

\section{Conclusion}

The observed clinical signs were positively correlated to Salmonella Antigen test, blood culture results, and stool results. However, this relationship was weak and not statistically significant. Other bacterial pathogens such as Staphylococcus species, Escherichia coli, Shigella species, and P. mirabilis in addition to Salmonella species was noted in those patients who presented with Fever-like symptoms. Due to over the counter misprescription of the drugs, poor utilization of the drugs and poor sanitation, high rate of multi-drug resistance could occur at the study site. There were no significant differences in gender, occupation, residence, age or clinic of the patients from which the isolates were obtained.

\section{Recommendations}

In addition to Salmonella species, Patients who present with Feverlike symptoms should be screened for other bacterial pathogens such as Staphylococcus species, Escherichia coli, Shigella species, and $P$. mirabilis since are associated with poor hygiene and sanitary conditions. The health officials should encourage the use of gold standard methods for diagnosis of Enteric fever. To reduce the cost of treatment and the emergence of resistant strains, the indiscriminate use of antibiotics should be discouraged. To discourage multiplication of these pathogenic bacteria that thrives in poor hygiene conditions, there is a need for improved hygiene in the living environment.

\section{Acknowledgments}

We sincerely thank Nairobi County Director of Health, Medical Director Crescent Medical Aid Kenya (CMA) and the staffs of Jamia Towers clinic.

\section{References}

1. Adabara NU, Ezugwu BU, Momojimoh A, Madzu A, Hashiimu Z, et al. (2012) The prevalence and antibioitic susceptibility pattern of Salmonella Typhi among patients attending a military hospital in Minna, Nigeria. Adv Prev Med 12: 347-351.

2. Buckle GC, Walker CL, Black RE (2012) Typhoid fever and paratyphoid fever: Systematic review to estimate global morbidity and mortality for 2010. J Glob Health 2: 010401.

3. Breiman RF, Cosmas L, Njuguna H, Audi A, Olack B, et al. (2012) Population-Based incidence of typhoid fever in an urban informal settlement and in Kenya: implications for typhoid vaccine use in Africa. PLoS ONE 7: e29119.

4. Kariuki S, Revathi G, Kiiru J, Mengo DM, Mwituria J, et al. (2010) Typhoid in Kenya is associated with a dominant multidrug resistant Salmonella Typhi halotype that is also widespread in South East Asia. J Clin Microbiol 48: 2171-2176. 
Citation: Musyoki PM, Kangethe SK, Ozwara H (2018) Characterization of Enteric Isolates in Blood and Stool Specimens among Outpatients Presenting with Fever Symptoms in Crescent Medical Aid Facility, Nairobi County, Kenya. Clin Microbiol 7: 322. doi: $10.4172 / 2327-5073.1000322$

Page 7 of 7

5. Kariuki S, Revathi G, Kariuki N, Kiiru J, Mwituria J, et al. (2006) Invasive multidrug-resistant non-typhoidal Salmonella infections in Africa: zoonotic or anthroponotic transmission? J Med Microbiol 55: 585-591.

6. Brooks WA, Hossain A, Goswami D, Nahar K, Alam K, et al. (2005) Bacteremic typhoid fever in children in an urban slum, Bangladesh. Emerg Infect Dis 11: 326-329.

7. House D, Wain J, Ho VA, Diep TS, Chinh NT, et al. (2001) Serology of typhoid fever in an area of endemicity and its relevance to diagnosis. J Clin Microbiol 39: 1002-1007.

8. Mweu E, English M (2008)Typhoid fever in children in Africa. Trop Med Int Health 13: 532-540.

9. Smith SI, Bamidele M, Fowora M, Goodluck HT, Omonigbehin EA, et al. (2011) Application of a point-of-care test for the diagnosis of typhoid fever in Nigeria and the need for improved diagnostics. J Infect Dev Ctries 5: 520-526.

10. Scrascia M, Forcillo M, Maimone F, Pazzani C (2003) Susceptibility to rifaximin of Vibrio cholerae strains from different geographical areas. J Antimicrob Chemother 52: 303-305.

11. Crump JA, Ramadhani HO, Morrissey AB, Saganda W, Mwako MS, et al. (2011) Invasive bacterial and fungal infections among hospitalized HIVinfected and HIV-uninfected adults and adolescents in Northern Tanzania. Clin Infect Dis 52: 341-348.
12. Moyo S, Aboud S, Kasubi M, Maselle SY (2010) Bacterial isolated from bloodstream infections at a tertiary hospital in Dar es Salaam, Tanzaniaantimicrobial resistance of isolates. S Afr Med J 100: 835-838.

13. Alam MS, Pillai PK, Kapur P, Pillai KK (2011) Resistant patterns of bacteria isolated from bloodstream infections at a university hospital in Delhi. J Pharm Bioallied Sci 3: 525-530.

14. Kang CI, Kim SH, Park WB, Lee KD, Kim HB, et al. (2005) Bloodstream infections caused by antibiotic-resistance gram-negative bacilli: risk factors for mortality and impact of inappropriate initial antimicrobial therapy on outcome. Antimicrob Agents Chemother 49: 760-766.

15. Wain J, Hosoglu S (2008) The laboratory diagnosis of enteric fever. J Infect Dev Ctries 2: 421-415.

16. Nkang AO, Okonko IO, Fowotade A, Udeze AO, Ogunnusi TA, et al. (2009) Antibiotics susceptibility profiles of bacteria from clinical samples in Calabar, Nigeria. J Bacteriol 1: 89-96.

17. Obiazi HAK, Nmorsi OPG, Ekundayo AO, Ukwandu NCD (2007) Prevalence and antibiotic susceptibility pattern of Staphylococcus aureus from clinical isolates grown at 37 and $44^{\circ} \mathrm{C}$ from Irrua, Nigeria. African J Microbiol Res 1: 75-60.

18. Yamashiro T, Nakasone N, Higa N, Iwanaga M, Insisiengmay S (1998) Etiological study of diarrheal patients in Vientiane, Lao people's democratic republic. J Clin Microbiol 36: 2195-2199. 